\title{
A neural field model for spatio-temporal brain activity using a morphological model of cortical connectivity Manh Nguyen Trong*1,2, Andreas Spiegler ${ }^{1,2}$ and Thomas R Knösche ${ }^{1}$
}

\author{
Address: ${ }^{1}$ Max Planck Institute for Human Cognitive and Brain Sciences, Leipzig, Germany and ${ }^{2}$ Institute for Biomedical Enginnering and \\ Informatics, Technical University Ilmenau, Germany \\ Email: Manh Nguyen Trong* - nguyen@cbs.mpg.de \\ * Corresponding author
}

from Eighteenth Annual Computational Neuroscience Meeting: CNS*2009

Berlin, Germany. 18-23 July 2009

Published: 13 July 2009

BMC Neuroscience 2009, I0(Suppl I):P287 doi:I0.I I86/I47|-2202-I0-SI-P287

This abstract is available from: http://www.biomedcentral.com//47/-2202//0/SI/P287

(C) 2009 Trong et al; licensee BioMed Central Ltd.

\section{Background}

Electroencephalography and magnetoencephalography (EEG and MEG) are brain signals with high temporal resolutions and are believed to reflect neural mass action. For modeling the neuronal structures, which are responsible for the generation of EEG/MEG, one can use so-called neural mass models, like the one of Jansen and Rit [1]. In such models, a brain area (e.g. a cortical column) is modeled by two or three neural masses subsuming similar cells, which are characterized by a single input-output relationship. It turns out that this type of model is too simple to reproduce the entire richness of typical EEG spectra. We therefore propose to use neural field models [2], which take into account the spatial dimension of active brain areas and describe the use of realistic local connectivity information in these models.

\section{Methods}

Dendritic and axonal arborizations need to be modeled for a formalized description of the connectivity between neurons and neural masses. The complex structure of these arborizations is represented with the help of trivariate Gaussian distributions (Figure 1). The number of the synaptic contacts will be weighted with the probability of synaptic connection and the gain of average postsynaptic potential. The neural field model is an extension to the neural mass model. The space in the model of the neural field, e.g. a cortical area or the entire cortex, could be defined as a homogeneous continuum of different neural masses with different structural properties. Interactions among neural masses of the neural field model can be described by a system of second order integro-differential equations and an embedded connectivity matrix. In the neural field model, not only the functions (excitatory and

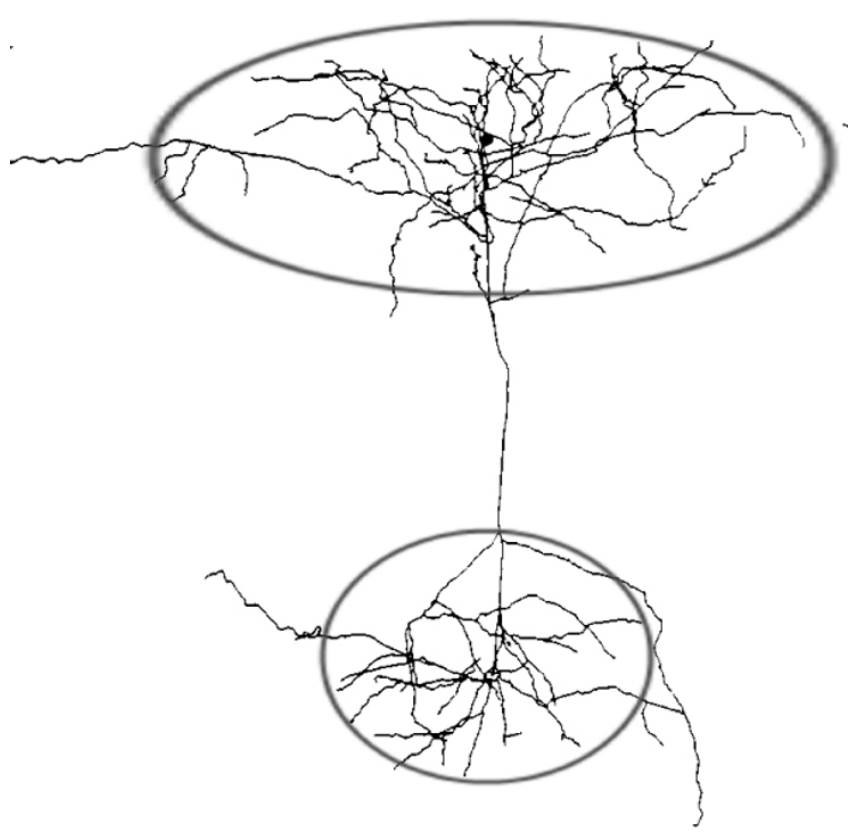

Figure I

Geometry of synaptic arbors. 


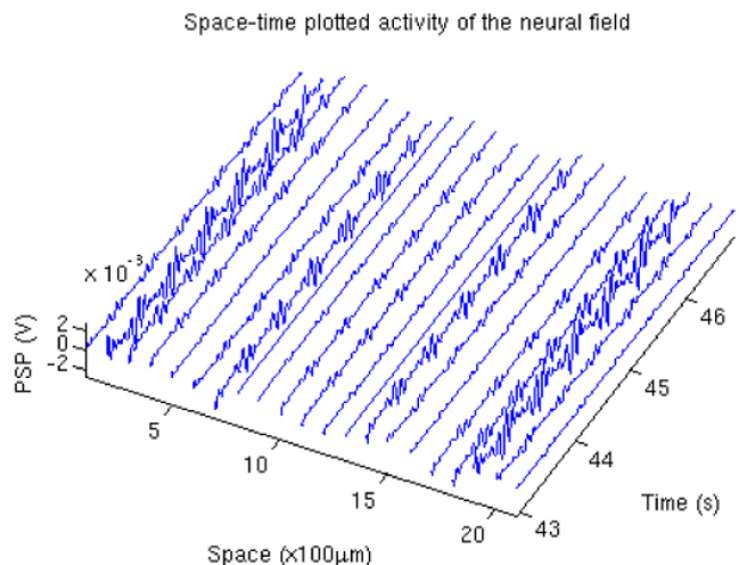

Figure 2

Spatiotemporal activity modeled pattern by the neural field model.

inhibitory) but also the morphology (pyramidal and nonpyramidal) of the neurons will be taken into consideration.

\section{Results}

The neural field model could produce a large variety of EEG-like waveforms and rhythms. In addition, this model is able to generate signals of multiple independent frequencies and spatiotemporal activity pattern (Figure 2).

We propose a new formalism to model neural fields and describe the incorporation of precise local connectivity information into these models. Our model is capable of producing output with very EEG-like time courses and spectra. Our results might constitute an important step on the road towards a universal model for neuronal mass action.

\section{References}

I. Jansen BH, Rit VG: Electroencephalogram and visual evoked potential generation in a mathematical model of coupled cortical columns. Biol Cybern 1995, 73:357-366.

2. Grimbert F: PhD thesis. University of Nice-Sophia Antipolis; 2008.
Publish with Biomed Central and every scientist can read your work free of charge

"BioMed Central will be the most significant development for disseminating the results of biomedical research in our lifetime. " Sir Paul Nurse, Cancer Research UK

Your research papers will be:

- available free of charge to the entire biomedical community

- peer reviewed and published immediately upon acceptance

- cited in PubMed and archived on PubMed Central

- yours - you keep the copyright

Submit your manuscript here:

http://www.biomedcentral.com/info/publishing_adv.asp 